\title{
STUDIES ON THE STRUCTURE AND PHYSIOLOGY OF THE FLIGHT MUSCLES OF BIRDS. 9. A QUANTITATIVE STUDY OF THE DISTRIBUTION PATTERN OF SUCCINIC DEHYDROGENASE IN THE PECTORALIS MAJOR MUSCLE OF THE PIGEON
}

\author{
J. C. GEORGE AND C. L. TALESARA \\ Laboratories of Animal Physiology and Histochemistry, Department of Zoology, \\ M. S. University of Baroda, Baroda, India
}

George and Naik (1958a, 1958b) have shown that the pectoralis major muscle of the pigeon consists of two distinct types of fibers, a broad glycogen-loaded white variety with few or no mitochondria and a narrow fat-loaded red variety having a large number of mitochondria in them. George and Scaria (1958) in a histochemical study of dehydrogenases (succinic, malic, lactic, and glycerophosphate dehydrogenases) in this muscle could not detect the presence of any of these dehydrogenases in the broad white fibers. They therefore concluded that these fibers in the pigeon breast muscle are a unique system in which none of the oxidative processes concerned with the above enzymes takes place and therefore cannot be considered as analogous to the white fibers of the other vertebrate skeletal muscles studied. These observations should naturally raise some important questions as well as doubts regarding the exact role of the broad fibers in this muscle and also the problem of energetics for their contraction. But, however, the above conclusions were based solely on histochemical observations and can be considered decisive only if supported by quantitative studies. Here we report the results of a quantitative study of the distribution pattern of the succinic dehydrogenase activity in the pectoralis major muscle of the pigeon.

\section{Material and Methods}

It is technically impossible by ordinary methods to estimate directly the activity of any enzyme in the two types of fibers in the pigeon breast muscle after isolating the fiber types separately. But the indirect method, viz. of estimating the activity of the enzyme in different layers of the muscle, where the broad and narrow fibers vary in number, was adopted in the present study. The fiber architecture of the pectoralis major muscle of the pigeon has been worked out in detail by George and Naik (1959). They have found that the least number of broad fibers is found in the fasciculi situated in the middle of the dorso-ventral axis of the muscle and the number tends to increase above or below this mark, reaching the maximum in the most superficial and in the deepest layers of the muscle. They also showed that per unit area of cross-section of the muscle at any particular depth, the number of broad fibers is inversely proportional to the number of narrow fibers, and derived the formula

$$
Y=-5.75 X+890.01,
$$


(where $Y$ stands for the number of narrow fibers and $X$ for the number of broad fibers) in order to estimate the number of narrow fibers in any one particular square $\mathrm{mm}$. area, $X$ being known. Throughout this study we made use of this formula for finding out the number of narrow fibers in a particular layer of muscle which was used for the estimation of the succinic dehydrogenase activity.

The method employed in the estimation of succinic dehydrogenase was the one according to Kun and Abood (1949) which makes use of the principle that colorless TTC (2,3,5-triphenyl tetrazolium chloride) is reduced to a red insoluble com-

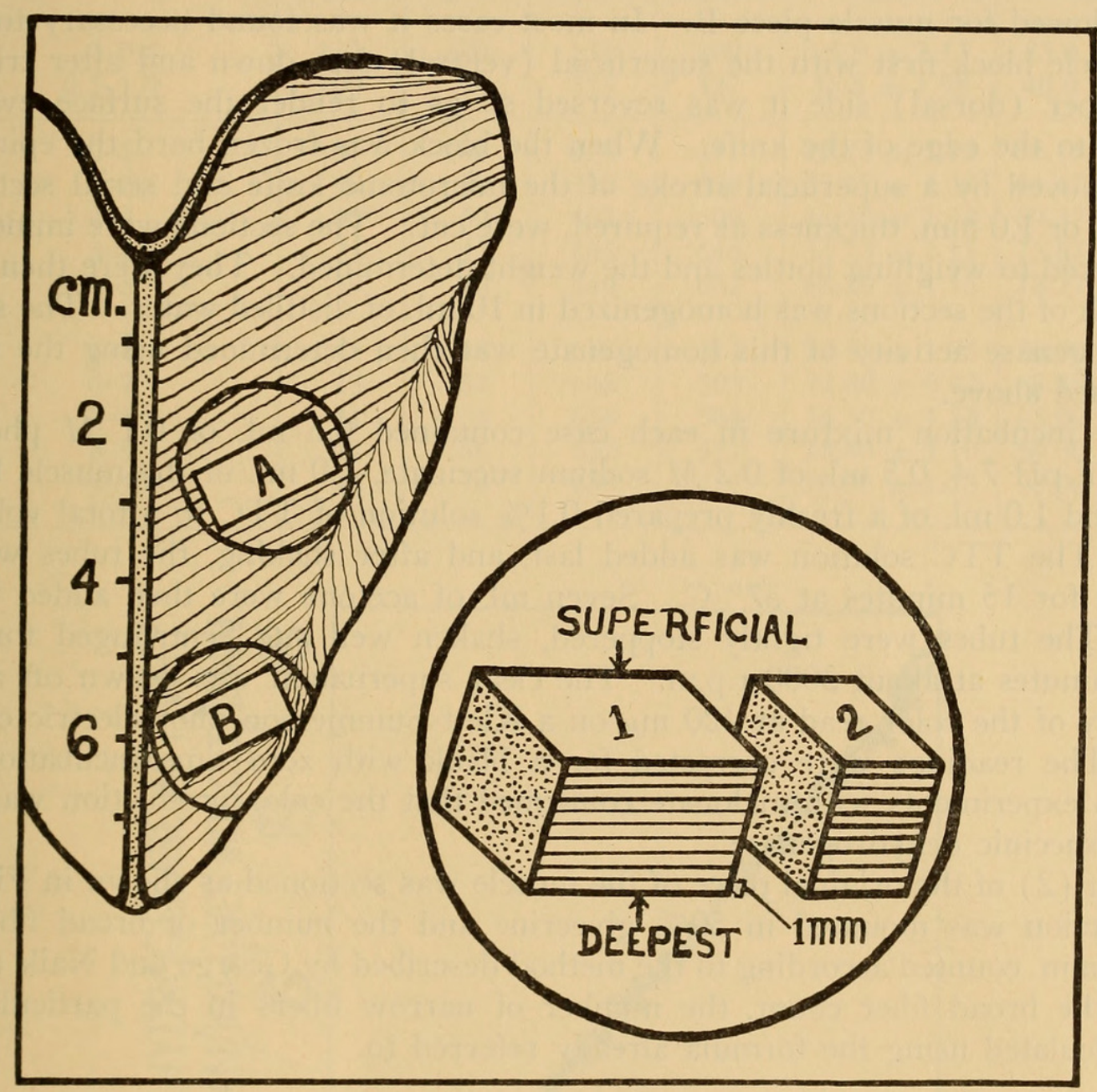

FIGURE 1. Illustrating the topography of the muscle pieces used for the study of succinic dehydrogenase activity in the pigeon breast muscle.

pound, formazan, by the enzymic oxidation of succinate to fumarate. The color developed was extracted in acetone and the intensity measured in a colorimeter. The amount of formazan formed was directly read from a standard curve plotted by reducing completely known quantities of TTC by sodium hydrosulphite. Since the reduction of TTC by hydrosulphite was found to be reversible, the color was stabilized by adding acetone within one minute of the addition of hydrosulphite to the TTC solution, during which time the TTC was completely reduced.

In order to ensure that only uniformly well developed pectoralis major muscle 
was used in the study, well fed and fully grown, normal laboratory pigeons (Columba livia) were used throughout.

In each experiment a bird was decapitated and the blood completely drained off. Pieces of muscle from the regions shown in Figure 1 ( $A$ and $B$ ) were cut off for each set of experiments. A portion (1) of this muscle piece A was immediately mounted on the stage of a freezing microtome with the superficial (ventral) side facing up, so as to obtain serial horizontal sections of the desired thickness starting from the superficial side of the muscle. The remaining portion (2) of the same piece was set apart for counting the broad and narrow fibers. The same procedure was followed for muscle piece B. In most cases it was found necessary to freeze the muscle block first with the superficial (ventral) face down and after trimming the deeper (dorsal) side it was reversed so as to render the surface even and parallel to the edge of the knife. When the block was frozen hard the epimysium was removed by a superficial stroke of the microtome knife and serial sections of $0.5 \mathrm{~mm}$. or $1.0 \mathrm{~mm}$. thickness as required, were cut. The sections were immediately transferred to weighing bottles and the weight determined. They were then chilled and each of the sections was homogenized in $10 \mathrm{ml}$. of distilled water. The succinic dehydrogenase activity of this homogenate was then determined using the method mentioned above.

The incubation mixture in each case contained $0.5 \mathrm{ml}$. of $0.1 M$ phosphate

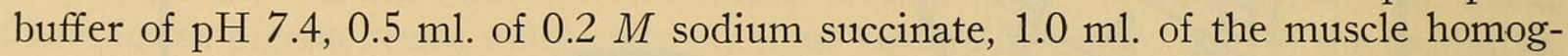
enate and $1.0 \mathrm{ml}$. of a freshly prepared $0.1 \%$ solution of TTC in a total volume of $3 \mathrm{ml}$. The TTC solution was added last, and after shaking, the tubes were incubated for 15 minutes at $37^{\circ} \mathrm{C}$. Seven $\mathrm{ml}$. of acetone were then added to each tube. The tubes were tightly stoppered, shaken well and centrifuged for about three minutes at about 3000 r.p.m. The clear supernatant was drawn off and the intensity of the color read at $420 \mathrm{~m} \mu$ on a Klett-Summerson photoelectric colorimeter. The readings were corrected for a blank with zero time incubation. Inhibition experiments with malonate confirmed that the color production was solely due to succinic dehydrogenase.

Part (2) of the original piece of the muscle was sectioned as shown in Figure 1. The section was mounted in $50 \%$ glycerine and the number of broad fibers per square mm. counted according to the method described by George and Naik (1959). From the broad fiber count, the number of narrow fibers in the particular area was calculated using the formula already referred to.

\section{RESULTS}

The dehydrogenase activity is expressed in the number of micrograms of formazan produced by $100 \mathrm{mg}$. wet weight of the muscle for 15 minutes at $37^{\circ} \mathrm{C}$. under the conditions of the experiment mentioned above. We do not claim that the values given are absolute because it is likely that freezing and thawing of the tissue in the process of cutting sections destroys a certain amount of its enzyme activity. However, this loss of activity could not be considerable and could be even neglected in view of the fact that our purpose is to compare the activity at the different depths and in relation to the number of the fibers per square $\mathrm{mm}$. area.

The succinic dehydrogenase activity and the number of broad and narrow fibers per square mm. in the different layers of the regions $\mathrm{A}$ and $\mathrm{B}$ of the breast 
TABLE I

Showing the succinic dehydrogenase activity in the different layers of the regions $A$ and $B$ (marked in Fig. 1) of the pectoralis major muscle of the pigeon and its relation to the number of narrow fibers. (The figures indicate the average values of five sets of readings.)

\begin{tabular}{|c|c|c|c|c|c|c|c|}
\hline \multirow[t]{2}{*}{ Exp. } & \multirow{2}{*}{$\begin{array}{l}\text { Depths of the muscle in } \\
\text { mm. starting from the } \\
\text { superficial side } \\
\text { (ventral face) }\end{array}$} & \multicolumn{2}{|c|}{$\begin{array}{l}\text { No. of broad fibers } \\
\text { per square mm. }\end{array}$} & \multicolumn{2}{|c|}{$\begin{array}{l}\text { No. of narrow fibers } \\
\text { per square mm. }\end{array}$} & \multicolumn{2}{|c|}{$\begin{array}{l}\text { Succinic dehydrogenase activity in } \\
\mu \mathrm{g} \text {. of formazan per } 100 \mathrm{mg} \text {. of } \\
\text { wet muscle per } 15 \text { minutes } \\
\pm \text { S.D. }\end{array}$} \\
\hline & & Region A & Region B & Region A & Region B & Region A & Region B \\
\hline 1 & $\begin{array}{r}0-0.5 \\
0.5-1.0\end{array}$ & $\begin{array}{l}132 \\
100\end{array}$ & $\begin{array}{r}120 \\
98\end{array}$ & $\begin{array}{l}131 \\
315\end{array}$ & $\begin{array}{l}200 \\
327\end{array}$ & $\begin{array}{l}15.5 \pm 2.17 \\
35.5 \pm 1.98\end{array}$ & $\begin{array}{l}23.0 \pm 1.18 \\
40.0 \pm 1.56\end{array}$ \\
\hline 2 & $\begin{array}{l}0-1 \\
1-2 \\
2-3 \\
3-4 \\
4-5 \\
\\
5-6 \\
6-7 \\
7-8 \\
8-9 \\
9-10\end{array}$ & $\begin{array}{r}107 \\
90 \\
86 \\
75 \\
59 \\
\\
45 \\
43 \\
41 \\
42 \\
45\end{array}$ & $\begin{array}{r}101 \\
59 \\
50 \\
43 \\
40 \\
\\
48 \\
52 \\
58 \\
66 \\
76\end{array}$ & $\begin{array}{l}278 \\
372 \\
402 \\
465 \\
549\end{array}$ & $\begin{array}{l}317 \\
558 \\
609 \\
646 \\
662\end{array}$ & $\begin{array}{l}32.22 \pm 1.12 \\
42.72 \pm 1.37 \\
46.25 \pm 1.44 \\
53.75 \pm 1.15 \\
63.25 \pm 1.73 \\
72.50 \pm 1.05 \\
72.80 \pm 0.92 \\
74.50 \pm 1.38 \\
73.40 \pm 2.10 \\
70.00 \pm 1.78\end{array}$ & $\begin{array}{l}36.75 \pm 3.13 \\
64.47 \pm 1.42 \\
69.37 \pm 0.82 \\
75.87 \pm 0.54 \\
78.77 \pm 1.32 \\
70.00 \pm 1.08 \\
68.50 \pm 2.16 \\
65.00 \pm 1.45 \\
59.00 \pm 2.80 \\
53.00 \pm 2.55\end{array}$ \\
\hline
\end{tabular}

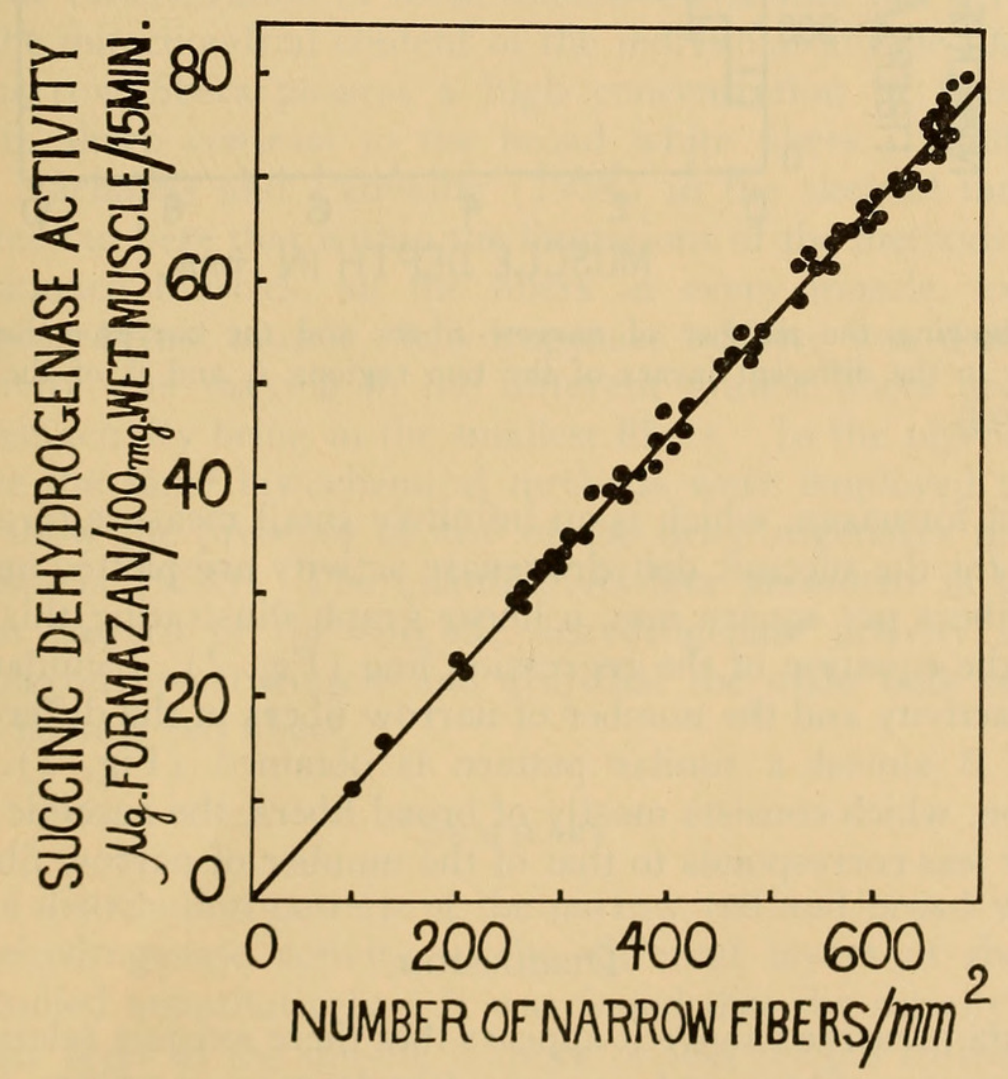

FigurE 2. Graph showing the relation between the number of narrow fibers and succinic dehydrogenase activity in the different layers of the pectoralis major muscle of the pigeon. 
muscle of the pigeon is shown in Table I. The results indicate that there exists a relationship between the activity of the enzyme and the number of narrow fibers per square $\mathrm{mm}$. in the different layers of the muscle. It was also decided to find out the activity of the enzyme in the $0.5-\mathrm{mm}$. thickness of the most superficial layers of $\mathrm{A}$ and $\mathrm{B}$ where the broad fibers are relatively much more concentrated than in the one-mm. thick layer (Table I).

From the results obtained the regression line is drawn using the equation

$$
S=0.3+.11478 Y \text {, }
$$

where $S$ stands for the succinic dehydrogenase activity and $Y$ for the number of narrow fibers in one square $\mathrm{mm}$. area. If the value of $Y$ is zero the value of $S$

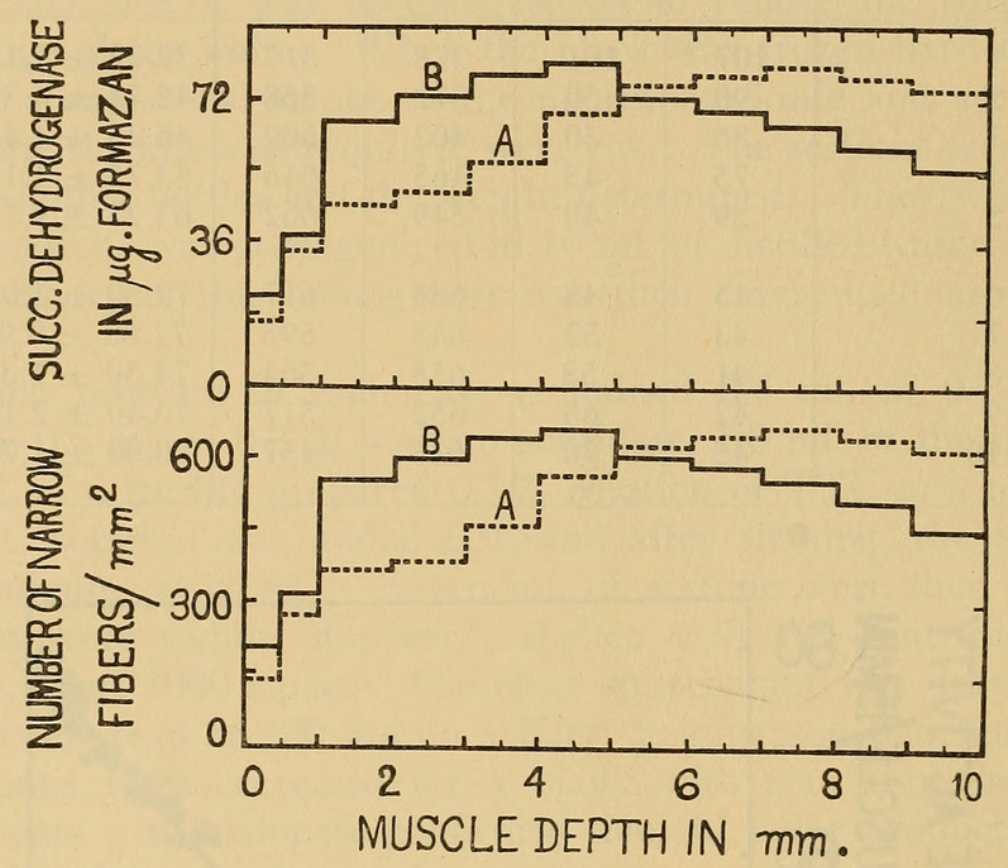

FIGURE 3. Showing the number of narrow fibers and the corresponding succinic dehydrogenase activity in the different layers of the two regions $\mathrm{A}$ and $\mathrm{B}$ of the pectoralis major muscle of the pigeon.

will be $0.3 \mu \mathrm{g}$. of formazan, which is an infinitely small measure of activity. If the values obtained for the succinic dehydrogenase activity are plotted against the number of narrow fibers per square $\mathrm{mm}$. a linear graph illustrating this relationship is obtained using the equation of the regression line (Fig. 2). Similarly plotting the dehydrogenase activity and the number of narrow fibers in the different layers from regions $\mathrm{A}$ and $\mathrm{B}$ almost a similar pattern is obtained (Fig. 3 ). In the most superficial region, which consists mostly of broad fibers, the succinic dehydrogenase activity more or less corresponds to that of the number of narrow fibers.

\section{Discussion}

From the data presented above it appears that there exists a relationship between the number of narrow fibers and succinic dehydrogenase activity in the different layers of the pigeon breast muscle. This relationship can be traced to the fact that 
the activity of the enzyme in the broad fibers is negligible. By substitution of the values in the formula mentioned above we obtain

$$
S=0.11478(890.01-5.75 X),
$$

(where $S$ stands for the succinic dehydrogenase activity in $\mu \mathrm{g}$. of formazan per $100 \mathrm{mg}$. of wet weight of the muscle taken from any region parallel to the surface of the muscle, per 15 minutes under the conditions of our experiment mentioned earlier, and $X$ stands for the average number of broad fibers per square $\mathrm{mm}$. area of cross-section of the muscle). In other terms

$$
\frac{S}{(890.01-5.75 X)}=K,
$$

(where $K$ is a constant, the value of which is 0.11478 ). This indicates that $S$ in any particular layer of the pigeon breast muscle is a function of the number of narrow fibers. The conclusion that can be drawn from this study is that in the pigeon breast muscle the main bulk of the succinic dehydrogenase is confined to the narrow fibers and that the broad white fibers possess only a negligible concentration of the enzyme.

George and Scaria (1958) and George, Susheela and Scaria (1958) studied, using histochemical methods, the activity of certain dehydrogenases in the breast muscle of the pigeon, fowl and bat and the leg muscle of the fowl and frog, and observed that the concentration of these oxidative enzymes has a relationship with the color and the mitochondrial content of the individual muscle fibers in the sense that the red narrow fibers possess a high concentration of these enzymes and mitochondria, in sharp contrast to the broad white fibers. Similar observations were made by Nachmias and Padykula (1958) in the skeletal muscle of rat. It should be pointed out here that within the limitations of the methods employed in all the above mentioned muscles, all the fibers in every muscle, except the broad ones of the pigeon breast muscle, dehydrogenase activity was detectable. Nevertheless the activity was varying in the different muscle fibers according to their diameter, highest activity being in the smallest fibers. In the pigeon breast muscle, however, where the same histochemical methods were employed the broad white fibers did not show the presence of any of the dehydrogenases mentioned earlier (George and Scaria 1958). The quantitative data presented in this paper show the distribution pattern of the succinic dehydrogenase activity in the different layers of the pigeon breast muscle and also that the main bulk of the enzyme is confined to the narrow red fibers.

\section{SUMMARY}

The relative distribution pattern of the narrow red and broad white fibers, and the succinic dehydrogenase activity in the different layers of the pigeon breast muscle were studied quantitatively. It was found that the activity of this enzyme in any particular layer of the muscle is more or less related to the number of the narrow red fibers present there since the main bulk of the enzyme resides in these fibers. 


\section{LITERATURE CITED}

George, J. C., ANd R. M. NAIK, 1958a. The relative distribution and the chemical nature of the fuel store of the two types of fibres in the pectoralis major muscle of the pigeon. Nature, 181: 709-710.

George, J. C., ANd R. M. NaIK, 1958b. Relative distribution of the mitochondria in the two types of fibres in the pectoralis major muscle of the pigeon. Nature, 181: 782-783.

GEorge, J. C., AND R. M. NaIK, 1959. Studies on the structure and physiology of the flight muscles of birds. 4. Observations on the fiber architecture of the pectoralis major muscle of the pigeon. Biol. Bull., 116: 239-247.

George, J. C., and K. S. Scaria, 1958. A histochemical study of the dehydrogenase activity in the pectoralis major muscle of the pigeon and certain other vertebrate skeletal muscles. Quart. J. Micr. Sci., 99: 469-473.

George, J. C., A. K. Susheela and K. S. Scaria, 1958. Studies on the structure and physiology of the flight muscles of bats. 3. Alkaline phosphatase and succinic dehydrogenase activity in the breast muscle-a histochemical study. J. Anim. Morph. Physiol., 5: $110-112$.

Kun, E., And L. G. Abood, 1949. Colorimetric estimation of succinic dehydrogenase by triphenyl tetrazolium chloride. Science, 109: 144.

Nachmias, V. T., and H. A. Padykula, 1958. A histochemical study of normal and denervated red and white muscles of the rat. J. Biophys. Biochem. Cytol., 4: 47-54. 


\section{$2 \mathrm{BHL}$ Biodiversity Heritage Library}

George, J C and Talesara, C L. 1960. "Studies on the structure and physiology of the flight muscles of birds. 9. A quantitative study of the distribution pattern of succinic dehydrogenase in the pectoralis major muscle of the pigeon." The Biological bulletin 118, 262-268. https://doi.org/10.2307/1539000.

View This Item Online: https://www.biodiversitylibrary.org/item/110976

DOI: https://doi.org/10.2307/1539000

Permalink: https://www.biodiversitylibrary.org/partpdf/2134

\section{Holding Institution}

Smithsonian Libraries

\section{Sponsored by}

Biodiversity Heritage Library

\section{Copyright \& Reuse}

Copyright Status: In copyright. Digitized with the permission of the rights holder.

License: http://creativecommons.org/licenses/by-nc-sa/3.0/

Rights: https://biodiversitylibrary.org/permissions

This document was created from content at the Biodiversity Heritage Library, the world's largest open access digital library for biodiversity literature and archives. Visit BHL at https://www.biodiversitylibrary.org. 